\title{
A method for measuring women climate vulnerability: a case study in Vietnam's Mekong Delta
}

\author{
Quang N.M. \\ Can Tho University, Can Tho, Vietnam
}

\begin{abstract}
Purpose - Across societies, gendered climate response decisions remain top-down and have limited progress because the influenced risk dynamics and their interrelations are not adequately understood. This study aims to address this gap by proposing an interdisciplinary innovative method, called women climate vulnerability (WCV) index, for measuring and comparing a diverse range of risks that threaten to undermine the adaptive capacity and resilience of rural women.
\end{abstract}

Design/methodology/approach - This paper builds on the literature to identify 12 risk categories across physical, economic and political sectors that affect rural women. These categories and attendant 51 risk indicators form the WCV index. A case study in Ben Tre Province (Vietnam) was used to demonstrate the application of the WCV methodology to rural contexts. The authors combined empirical, survey and secondary data from different sources to form data on the indicators. Structured expert judgment was used to address data gaps. Empirical and expert data were combined using a few weighting steps and a comprehensive coding system was developed to ensure objective evaluation.

Findings - The WCV assessment results reveal a reasonably worrisome picture of women's vulnerability in Ben Tre as top highest-likelihood and deepest-impact risks predominate in physical and economic risk sectors. Stability, human security and governance categories have lowest scores, demonstrating a fairly politically favourable condition in the province. The medium risk scores captured in land and infrastructure categories reveal promising determinants of the adaptation of women in this rural province. The results

(C) Quang N.M. Published by Emerald Publishing Limited. This article is published under the Creative Commons Attribution (CC BY 4.0) licence. Anyone may reproduce, distribute, translate and create derivative works of this article (for both commercial and non-commercial purposes), subject to full attribution to the original publication and authors. The full terms of this licence maybe seen at http://creativecommons.org/licences/by/4.0/legalcode

This paper is part of the research grant \# 1747-20-100-7202-20 funded by the East-West Management Institute (EWMI) through Open Development Initiative (ODV). The authors would like to express their sincere thanks to EWMI, Ms Pyrou Chung (ODV Director), Ms Nga Nguyen and Ms Hoang Anh (Open Development Vietnam) for their generous support and technical assistance related to data collection and virtualisation during the course of the project. Special thanks go to women respondents and local government officials in Ben Tre Province, who spent their valuable time for the interviews and provided data without which this research has little to rest on. The authors are grateful to the following citizen scientists from Can Tho University and Mekong Environment Forum who have overcome the challenges from pandemic to complete fieldwork and data collection in the research site: Ho Thi Thu Ho, Le Van Hieu, Huynh Hoang Kha, Le Thanh Nghe, Trinh Chi Tham, Phan Hoang Linh, Tran Thi Minh Tho, Nguyen Hoai Phong, Tran Thi Diem Suong, Nguyen Thi Anh Tuyet, Nguyen Van The, Duong Quoc Bao, Nguyen Thi My Yen and Thai Kim Nhi. This research is initially inspired by the research work of Gupta et al. (2007), Dube (2014) and Stuart et al. (2020). The author is indebted to their literary contributions and other authors and organisations whose publications were cited in this work. Finally, the authors want to thank Wesley Grover (MEF copyeditor) for casting his experienced eyes over sections of the paper.

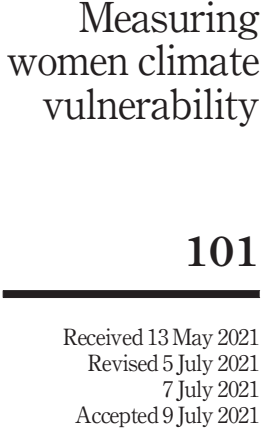


IJCCSM 14,2

102 demonstrate the usefulness of the WCV index in collecting bottom-up data, evaluating a wide variety of risks that rural women face and pinpointing priority areas that need to be addressed.

Originality/value - The WCV is systematic, customisable and localised. It combines field research and empirical data through structured expert judgment, thus enables researchers to fill data gaps and to do evidence-based assessment about diverse risk vulnerabilities. By doing so, the WCV index gives critical insights into the challenges that rural women face. This enables local governments to better understand crosssectoral risks, pinpoint priority areas of action and timely channel funding and policy resources to support women where they need it most.

Keywords Women climate vulnerability, Climate risk assessment, Mekong Delta, Gender inequality, Women adaptive capacity, Climate adaptation

Paper type Research paper

\section{Introduction}

There is ample evidence that women are more susceptible and exposed to climate change than men, given their socially constructed roles and responsibilities within the home, as well as the community (UNFCCC, 2019a; FAO, 2017; IUCN, 2015). In developing countries, women are a crucial labour force in rural economy. As climate hazards get worse, women are forced to shoulder increased workload at home because of the outward migration of men. Additionally, rural women are more marginalised in political and household decisions that affect their lives because they often face patriarchy cultural norms and negative stereotypes that limit their capability to respond to climate change effects (Figueiredo and Perkins, 2013; Boetto and McKinnon, 2013; IUCN, 2015; UNDP, 2013).

Increased gender inequalities through climate change have repeatedly been called to attention in the past decade (Denton, 2010; Resurrección, 2013; Djoudi et al., 2016; UNFCCC, 2019a; FAO, 2017; IUCN, 2015; UNDP, 2013). This problem calls for action at the local, national and global levels to deal with the underrepresentation of women in decision-making spheres as a means of enhancing their support systems and coping capacity.

The literature has focussed primarily on the disproportionate impacts of climate change on women and gender inequality, assessing the limits of political and institutional frameworks to deal with such problems, both nationally and internationally. Much research work has also focussed specifically on African contexts. Some other work further examines the important role of women in efforts at local level adaptation and mitigation (Whyte, 2014; Glazebrook, 2011; Figueiredo and Perkins, 2013; IUCN, 2015). However, there is little research work that identifies and quantifies the climate change vulnerability risks facing rural women - who are often poor and dominate the developing world. The integration of gender considerations into national climate policies occurs slowly and the gendered evidence-based decision-making in climate actions occurs even more slowly. Without understanding of the potential risks that constitute the vulnerability of women, governments may not be able to pinpoint areas of greatest risk and thus fail to channel timely investment to help where women are needed most. This highlights a need for womencentred, comprehensive, context-specific assessments that enhance the protection and adaptation of rural women.

Against this background, this paper seeks to address the question:

Q1. How can the risk factors that threaten to undermine the adaptive capacity and resilience of rural women be assessed and measured?

This question will be applied to the issue of gender-based climate adaptation and mitigation. From an interdisciplinary research perspective, it becomes critical to identify inter-sectorial 
risk indicators across the ecological, economic, security and political spheres that rural women face and impact their risk of being left behind in the fight against climate change. These indicators are represented in an interdisciplinary analytical tool called women climate vulnerability (WCV) index to measure and compare a diverse range of risks to produce women climate risk profile in the Mekong Delta of Vietnam, one of the world's most vulnerable deltas to climate change. The WCV index was used in Ben Tre Province as a case study to demonstrate the application of WCV index. In doing so, a research protocol for applying this assessment methodology emerges naturally. It concludes with a discussion as to why a WCV assessment matters for gender-sensitive climate policy reforms.

\section{Analytical framework: formation of women climate vulnerability index}

\subsection{An interdisciplinary approach to women climate vulnerability assessment}

Climate change is a global cross-cutting problem that is local in nature (Gupta et al., 2007; Quang, 2020). As the root causes and manifestations of climate risks vary significantly across countries, vulnerability assessment requires an integrated approach that is grounded in local realities and helps governments quantify locally specific potential vulnerability carriers that underpin negative experiences that women face. Localisation of WCV assessment helps localise international and national agendas to meet local needs and ensure that no one is left behind.

Rural women have been recognised as one of the most vulnerable groups to the negative impacts of climate change. They live in rural contexts in which geophysical, socio-economic and political realities form their adaptive capacity. The amount of resources and opportunities available to women, how women are empowered in economic and political processes, and the degree to which their community is exposed to natural hazards are among critical factors in adaptation (Nyirongo, 2019). Climate change is expected to increase risks and vulnerabilities as well as to modify the conditions that shape the adaptive capacity of women, given their huge dependence on natural assets and marginal status in political and economic spheres. Also, the broader socio-economic and political relations in their community shape their responsive capacity through access to resources, information, policy benefits and the availability of options and choices (Tschakert, 2012). Thus, vulnerability indicators vary across sectors and provinces. While much literature and political attention focusses on the increased gender inequalities and women adaptive capacity building (UNFCCC, 2019a; FAO, 2017; IUCN, 2015; Andrijevic et al., 2020; Banerjee et al., 2019), less attention has been paid to assessing risk indicators in a particular community to ensure that local climatic and non-climatic drivers of vulnerability are fully understood, properly quantified and incorporated into future planning decisions. Thus, a localised interdisciplinary vulnerability assessment tool is needed to provide insights into the concrete root causes of climate risk vulnerability at the local level, enabling decision makers to develop policy responses that are possible at multiple administrative levels. The aim of this research is not to review the literature on climate vulnerability, on risks and on adaptation and resilience. It is to articulate these broad concepts in such a way that they can be of use to frame an approach applicable to comprehensively assess and measure the degree to which rural women would experience the negative impacts of climate change and how their living conditions across physical, economic and political spheres contribute additional threats that further undermine their adaptive capabilities.

Rural women often face physical, socio-economic and political barriers that limit or even challenge their adaptation and resilience (UN Women Watch, 2022; Nyirongo, 2019). When coupled with extreme weather conditions, those barriers would probably amplify the disproportionate impacts of climate change on women, placing them in a position where 
IJCCSM 14,2

104

they are unable to cope with the changing environment and, thus, their uncertain futures. Seen in this way, physical changes and economic and political drivers are intrinsically intertwined, having the potential to introduce new uncertainties that increase the likelihood of a double crisis and more risks to rural women. This research builds on ample literature to understand common rural contexts and livelihoods women often survive on and to identify determinants of climate adaptive capacity that are in line with the specific characteristics of rural women.

\subsection{Risk categories and indicators}

2.2.1 Physical risk. In rural contexts, women are more vulnerable to climate change effects because their livelihoods are completely reliant on natural assets which are no longer stable and predictable. Changes to natural sources, water security, land use and ecosystem health have clear and present impacts on the livelihoods, economic security and safety of women (Landis et al., 2013; UN Women Watch, 2022). Natural hazards and geographical factors such as coastal erosion, land subsidence, groundwater and forest degradation provide important metrics to understand the environmental challenges that have the potential to exacerbate the severity and frequency of climate change effects in a particular community. Some physical risks are the root causes of climate change, while some acute events, like climate hazards, wildfires and extreme heat, are the consequences of the changing climate. Based on this background, we identify four categories - Water, Land, Climate and Ecology and attendant 12 risk indicators that form the physical risk (Table 1). In this research, all risk indicators are named concisely or abbreviated to ensure legibility.

2.2.2 Economic risk. The climate change impacts disproportionately affect the economic and food security and thus the well-being of rural women and their potential to contribute towards sustainable development (Nyirongo, 2019). Some factors, such as public infrastructure, energy and livelihoods, are also highly susceptible to hazards (Momtaz and Asaduzzaman, 2020). The economic risk considers economic vulnerability of women by assessing the degree of their ability in adapting and recovering from economic shocks as a result from climate hazards associated with other physical and political risks. As more men tend to migrate to find employment opportunities in big cities, women have to learn to deal with new challenges on their own. However, economic dependency excludes women from important resources, including property ownership and decision-making power, so that they have less access to adaptive opportunities (Balabanova, 2007). In some circumstances, pressure to secure family incomes could induce women to get involved in conflicts over water and land resources or worse, to get trafficked (International Organisation for Migration, 2017; Binh, 2018). Additionally, failure to access policy preferences and climate financial support likely increase the participation of women in informal economic and financial activities, which eventually lead them to direr destitution. Finally, early evidence demonstrates that economic insecurity risks, such as a lack of economic self-reliance, unemployment and famine and poor housing conditions can fuel violence against women and girls, including domestic violence, sexual harassment and rape (UNFCCC, 2019b; Gevers et al., 2020). Table 2 presents 19 indicators that constitute three categories of the economic risk - economy, livelihood and infrastructure.

2.2.3 Security and political risk. Some research work has demonstrated the causal relationship between climate change and political instability in developing countries. Rising temperature, prolonged droughts and flooding are among negative impacts of climate change that likely lead to social disorder or conflicts over resources (Sofuoğlu and Ay, 2020). On the other hand, potential drivers of political unrest, like human insecurity, poor governance, refugee crisis, misinformation and resource scarcity, can reduce the resilience of 


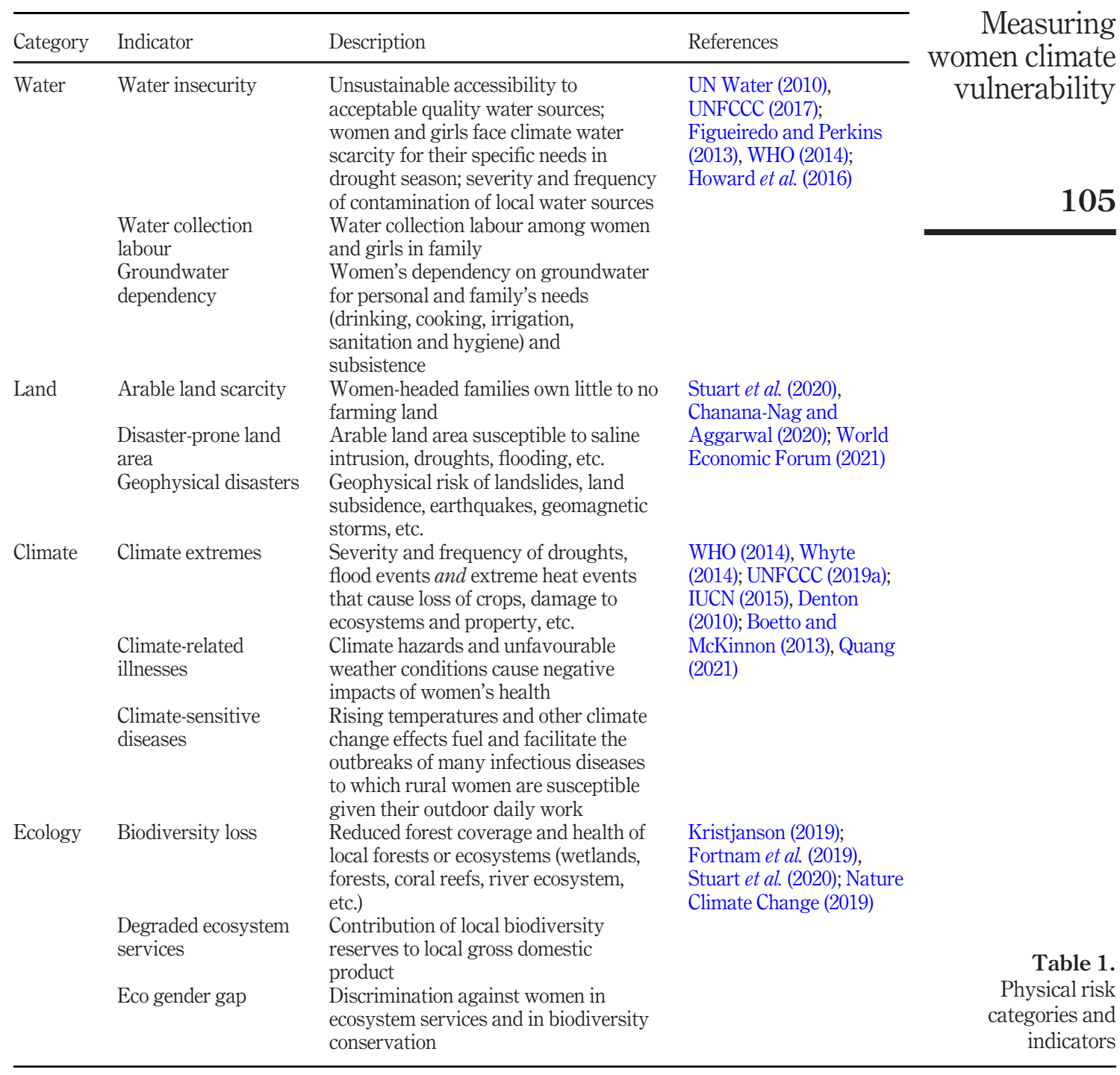

women and increase social tensions when they intersect with extreme hazards and economic pressures such as high unemployment rate and livelihood crises (Stuart et al., 2020; UN Women Watch, 2022). Lack of gender-sensitive governance, women's marginalisation, environmental myths and misperception about women's rights are among other challenges impeding women to be aware of how to access appropriate support and unable to make informed decisions regarding climate adaptation and how to engage with formal institutions and what to expect. Other human security threats from chronic and persistent poverty to 


\section{IJCCSM \\ 14,2}

106

\begin{tabular}{ll}
\hline Category & Indicator \\
\hline Economy & $\begin{array}{l}\text { GNI per capita } \\
\text { decline }\end{array}$ \\
& Unequal \\
property rights \\
\\
\\
Lack of income \\
diversification \\
\\
\\
Rural \\
unemployment \\
Economic \\
dependency
\end{tabular}

Financial

illiteracy

Informal

economy

Tax burdens

Livelihoods Cultivation

recession

Husbandry recession

Aquaculture recession

Wild-capture fishery recession

Table 2.

Economic risk categories and indicators

Factory jobs recession

\section{Description \\ References}

Low GNI per capita of rural women prevents them from education and development opportunities

Lack of ownership rights to real property, farming land and other valuable assets eliminate women's confidence, autonomy and decision-making power at home Income diversification helps rural women to enhance their resistance and resilience to climate hazards and stabilise family economic security

Unemployment rate of women

Economic dependency reduces individual freedom and rights of a woman and excludes her from important resources needed for development

Lack of competency in financial literacy leads women to face serious repercussions, such as credit card debt, miscalculation in investment or business and failure to manage income, taxes and investments

Proliferation of informal or illegal economic and financial activities in rural areas threatens to undermine women's economic security and cause family fragmentation or violence against women

Women's income is usually lower than men's. High taxation may reduce their financial ability in times of crisis (e.g. pandemic and climate hazards) or influence their economic welfare in the case of a divorce

Risk is very likely to occur if the income of a woman is primarily dependent on cultivation (rice farming, orchards, floral crops, etc.) in the face of climate variability

Income primarily dependent on animal husbandry (pigs, poultry, etc.) is likely in danger of pandemic, climate hazards and economic shocks

Climate hazards and human-induced environmental crises (e.g. water pollution) pose high-risk to income of women that is primarily dependent on aqua farming livelihoods

A woman primarily dependent on wild fish caught in either saltwater or freshwater (artisanal fishing) for her subsistence is highly vulnerable to climate extremes and environmental crises
Smit and Pilifosova

(2001), Balabanova (2007); OECD (2013), Leonard (1998);

Arekapudi and

Almodóvar-Reteguis (2020); UN Human

Rights (2012), Valodia (2009); Wan et al.

(2016)

Momtaz and

Asaduzzaman (2020), Stuart et al. (2020); UN Population Fund (2009), FAO (2017) 


\begin{tabular}{|c|c|c|c|c|}
\hline Category & Indicator & Description & References & $\begin{array}{l}\text { Mleasuring } \\
\text { hen climate }\end{array}$ \\
\hline & $\begin{array}{l}\text { Economic } \\
\text { stagnancy }\end{array}$ & $\begin{array}{l}\text { Higher-paying jobs in service sectors } \\
\text { (tourism, trading, education, healthcare, etc.) } \\
\text { stabilise women's economic security }\end{array}$ & & vulnerability \\
\hline \multirow[t]{7}{*}{ Infrastructure } & $\begin{array}{l}\text { Poor public } \\
\text { infrastructure }\end{array}$ & $\begin{array}{l}\text { Insufficient public infrastructure, including } \\
\text { transportation system, constrains rural } \\
\text { women to fulfil their basic needs, impedes } \\
\text { economic development, access to education }\end{array}$ & \multirow{7}{*}{$\begin{array}{l}\text { UN Women Watch } \\
\text { (2022), Denton (2010); } \\
\text { Indrawati (2015), } \\
\text { OECD (2018); UN } \\
\text { Human Rights (2012) }\end{array}$} & 107 \\
\hline & Poor digital & $\begin{array}{l}\text { and health care and social inclusion } \\
\text { Less developed communication and }\end{array}$ & & \\
\hline & infrastructure & $\begin{array}{l}\text { technological infrastructure enlarges } \\
\text { development gaps between rural and urban } \\
\text { societies, reducing development opportunities } \\
\text { for rural women }\end{array}$ & & \\
\hline & $\begin{array}{l}\text { Inadequate } \\
\text { housing }\end{array}$ & $\begin{array}{l}\text { Women and girls live in unsafe and poor } \\
\text { conditions: limited access to safe water, } \\
\text { energy, transportation and public services; } \\
\text { lack of other facilities providing privacy. Poor } \\
\text { housing conditions increase vulnerability of } \\
\text { women and girls to sexual abuse, rape and } \\
\text { harassment }\end{array}$ & & \\
\hline & $\begin{array}{l}\text { Lack of } \\
\text { emergency } \\
\text { shelters }\end{array}$ & $\begin{array}{l}\text { Limited free access to emergency shelters or } \\
\text { temporary housing when facing family } \\
\text { violence and abuse or disasters, threaten to } \\
\text { place women at risk and could lead to refugee } \\
\text { crisis }\end{array}$ & & \\
\hline & $\begin{array}{l}\text { Energy } \\
\text { insecurity }\end{array}$ & $\begin{array}{l}\text { Limited access to power and lack of energy } \\
\text { diversification increase vulnerability to } \\
\text { power disruptions, narrow livelihood options } \\
\text { and undermine women's economic } \\
\text { empowerment and advancement }\end{array}$ & & \\
\hline & & & & Tabl \\
\hline
\end{tabular}

human trafficking, to cyber-attacks, pandemics and sudden financial downturns can reduce the ability of women to effectively respond to the climate emergency. Table 3 shows five categories of security and political risk: demographics, governance, stability, cyber security and human security which are made up of 20 indicators.

\section{Application of women climate vulnerability index: case study in the Mekong Delta}

To understand and measure the risk vulnerabilities that have the potential to undermine the coping capacity of women in the Mekong Delta and identify the priority areas in need of action, we have conducted in-depth studies to build a WCV index profile in Ben Tre Province (Figure 1). The province was selected in view of its physical, economic and political contexts that best represent those of the Mekong Delta.

Geographically, Ben Tre is a medium-sized province by land area and population. Home to nearly 1.3 million people, $51 \%$ of which are women and less than $10 \%$ of the population live in urban areas, and Ben Tre is a typical rural, low-lying province in the Delta. The province is noticed for its agricultural and aquaculture strengths which dominate the local economy. Rice crops, coconut farms, floriculture and shrimp farming are the primary sources of income of small-scale farmer households. These livelihoods predominate the land 


\begin{tabular}{l} 
IJCCSM \\
14,2 \\
$\mathbf{1 0 8}$ \\
\hline
\end{tabular}

$\mid$

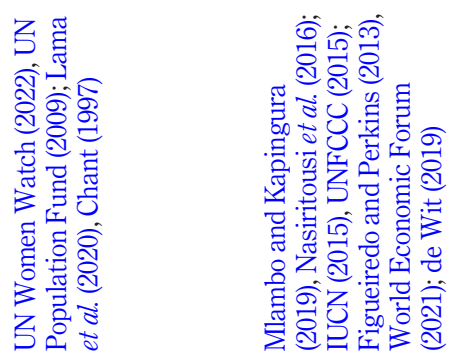

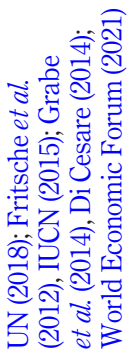

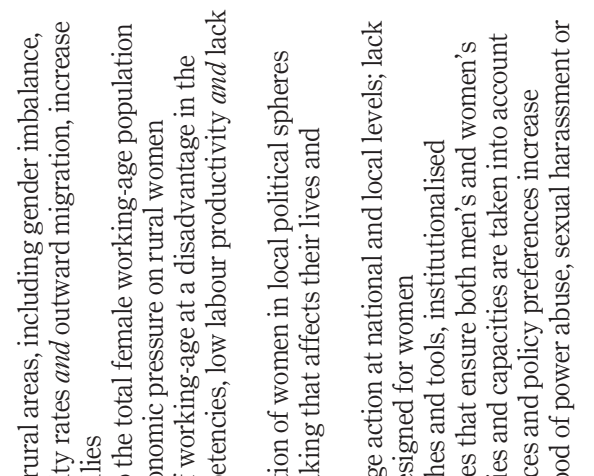

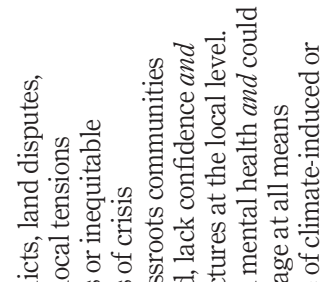

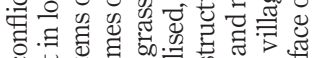

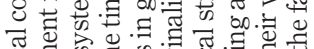
उ

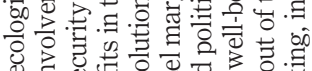

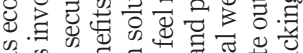
o w 矛 क

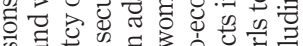

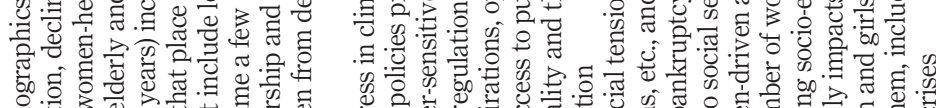

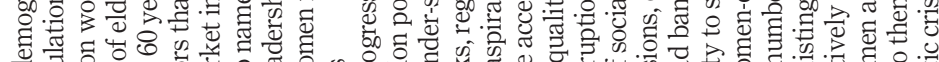
0

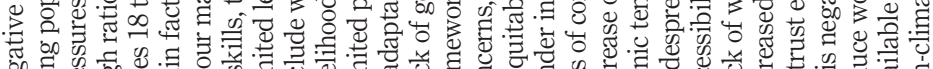

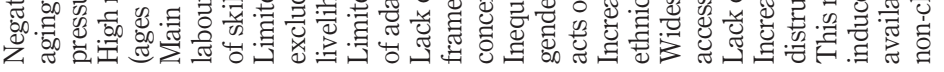

Table 3.

Security and political risk categories and indicators
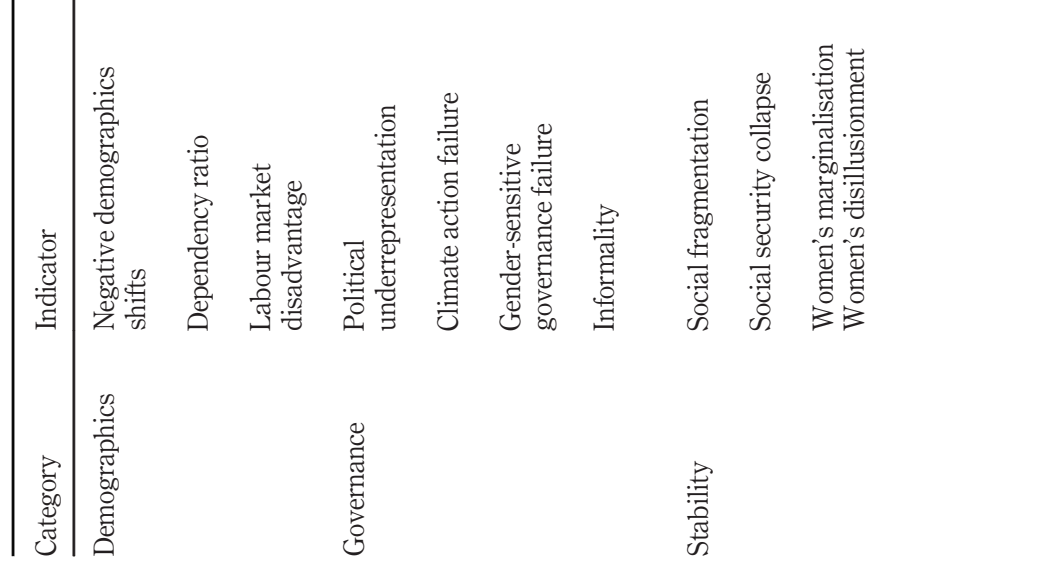


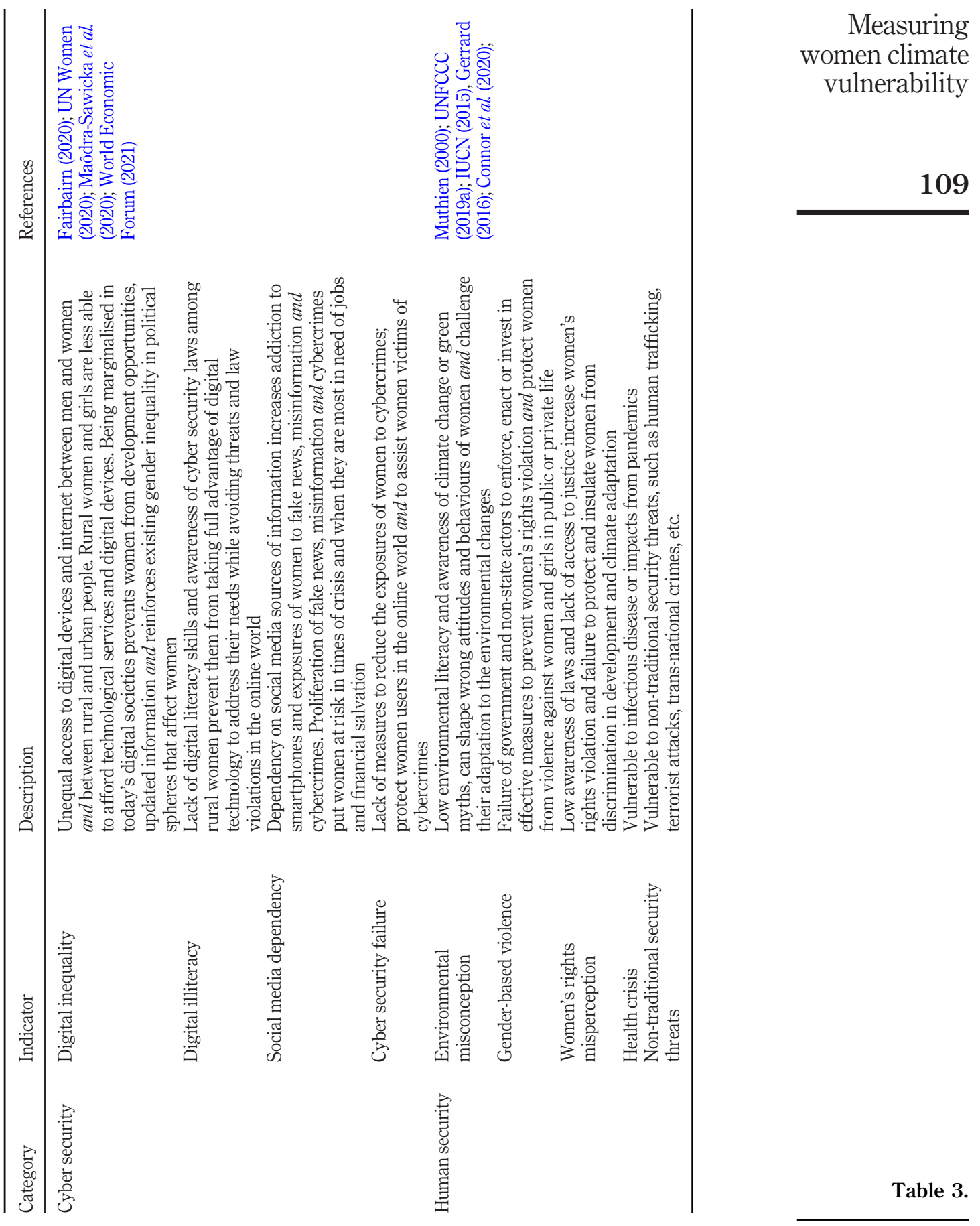




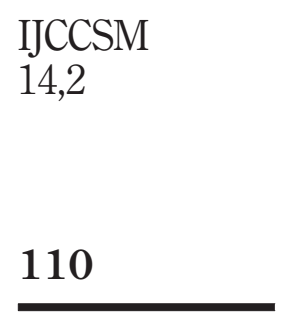

Figure 1.

Field research sites (highlighted in black squares) in Ben Tre Province

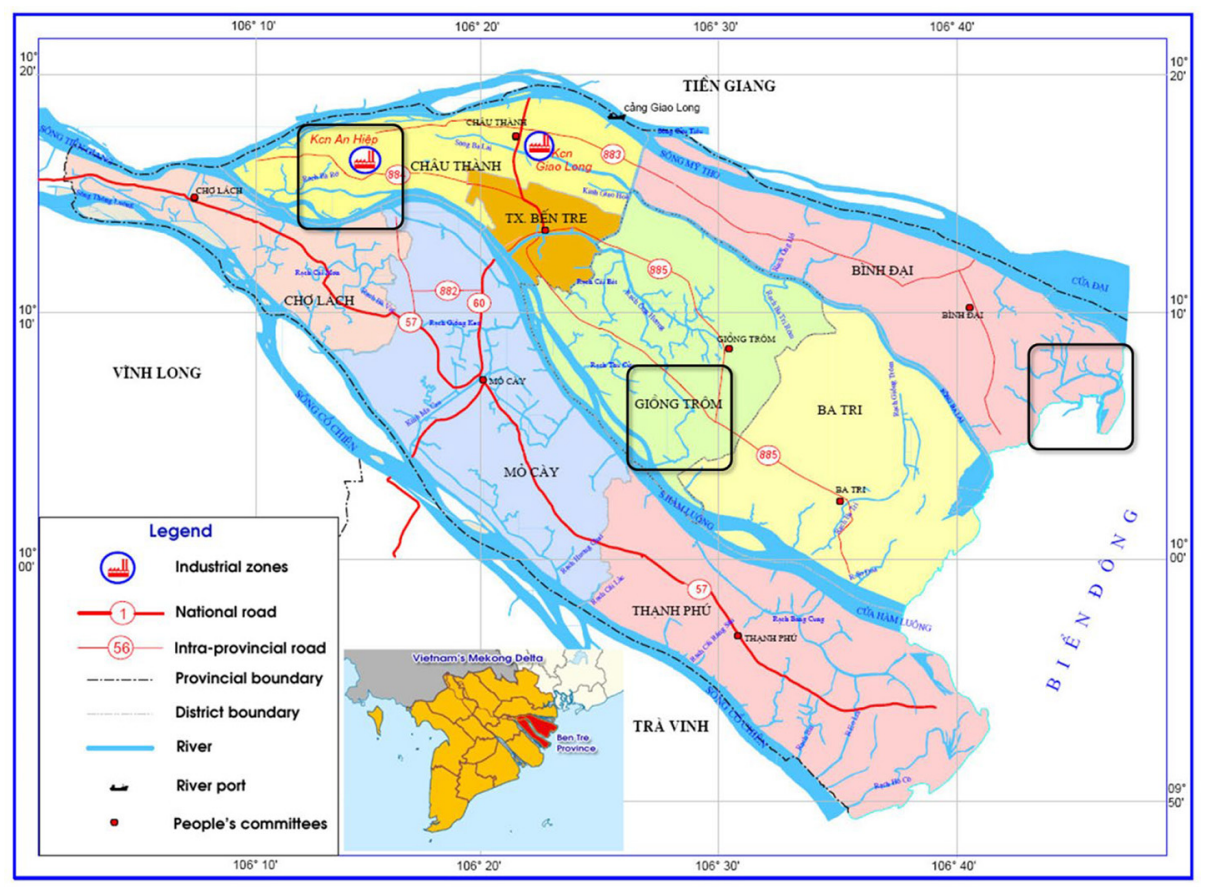

Source: Adapted from ben tre people's committee (2021)

use $(83 \%)$ and completely rely on freshwater supply from the Mekong River estuaries. Gender inequality can be seen in these agricultural industries. Female workers dominate in paddy fields, coconut farms and flower plantations where low-cost, seasonal labourers are needed. Ben Tre is among the top three provinces that have the largest number of outward migrants in the Mekong Delta (Ben Tre People's Committee, 2021).

Among the provinces often hit hardest by disasters, Ben Tre is most at risk due to its geographical and economic vulnerabilities. Recent sea level rise impact assessments conclude that over $50 \%$ of the province area $(1.131 \mathrm{sq} . \mathrm{km})$ will be permanently flooded by 2,100 (Carew-Reid, 2008; Ministry of Natural Resources and Environment, 2016). Climate change is predicted to impact the province more seriously in the coming decades. Climate hazards, such as extreme heat events, droughts and sea level rise, are expected to become more intense in the province due to reduced precipitation, rising temperatures and El Nino events.

\section{Methodology}

\subsection{Risk assessment}

Indicators presented in the WCV index categories provide detail on a vast array of climateinduced and anthropogenic risks that impact the adaptive capacity and resilience of rural women. Assessing risk is based on severity and likelihood of occurrence and includes an analysis of threats based on its nature and impact on women. As potential risks are identified, they are measured by determining how probable it is that a threat will occur and its potential impact on women in short- and long-term. Five factors that constitute the 
holistic risk rating include past, current and expected trends, the rate of change in the risk and the impact of this risk to women in a particular community.

\subsection{Field research and data collection}

We combined empirical, survey and secondary data from different sources, including document analysis, in-depth interviews and household surveys to form data on 51 indicators across 12 risk categories. By doing so, we have produced a data set that enables us to compare climate risk across multiple sectors, from physical changes to socio-economic shifts to political capacity. We first scrutinised and analysed 136 policy documents and research publications pertaining to climate change impacts, adaptation responses, demographics, infrastructure, political decentralisation and governance and human security published by state agencies, local researchers and international development partners. This method provided data on the past trend and baseline of each risk indicator.

Primary data were collected from our field research in Ben Tre Province using the Epicollect5 mobile app. Three fieldwork teams were recruited and trained by experts from the Open Development Vietnam and Mekong Environment Forum in September and November 2020 in research ethics, data collection, data processing and visualisation, among other training topics. Each team comprised two senior researchers, four to six graduate students majoring in environmental studies, social science and geography and two local liaisons that helped handle administrative and logistics arrangements.

As the research involved the collection of personal and household data, excluding personally identifiable information, the research team members explained to the respondents how their data will be used and explicitly stated that their participation in the research, as well as their data, will always be kept confidential. All respondents were advised in advance that they do not need to answer any questions which they may be uncomfortable responding to due to the personal or sensitive nature of the subject and they can stop the interview at any time. Because written consent is not appropriate due to a fear among local people that signing survey documents may lead to personal data leaks or risk, we preferred using oral consent. All data/answers were anonymised immediately upon completion of the interview and automatically synchronised with a SURF Drive account on the researcher's mobile/laptop device.

Field research activities have been conducted in three communes at the same time by the research teams, in October 2020 (six days), January and March 2021 (eight days). The indepth interviews with local women and experts were conducted in an informal and comfortable atmosphere that provided us with a clear context to identify risk dynamics and information needed to fill data gaps and for triangulation purpose. Three hundred and ninety women were selected for surveys and interviews in three communes (130 women each) using systematic sampling method as follows. The sample size was calculated with the margin of error or confidence interval $=0.05$ and confidence level $=95 \%$. Selected women respondents are from different ages, job titles, livelihoods and from different villages in the three communes. The researchers helped women to fill in questionnaires in Epicollect5 that contain the same open-ended and close-ended nature questions personally, which are structured around the above-mentioned five indicator factors. Forty-five women respondents and 25 senior university experts and local government leaders were involved in our semi-structured interviews (30 to $50 \mathrm{mins}$ each) to provide further information and insights related to the risk indicators that concerned local women. The interviewed experts and local officials are those who have at least 10 years of experience in research or working in fields related to the research topics. All interviews were recorded with oral consent of the interview subjects. 
IJCCSM

14,2

112

\subsection{Structured expert judgment}

To address the data gaps, we used the structured expert judgment, a widely used technique in quantitative and qualitative risk analysis when existing empirical data is unavailable or inadequate (Stuart et al., 2020; van Steen, 1992). Senior experts recruited in this research include university researchers, independent experts and senior government officials who have recognised expertise and experience in fields of study related to the risk categories in the index. To avoid confirmation bias and ensure structured elicitation of multivariate uncertainty from experts, survey answers are compared to field research and government sources data to triangulate and weight the expert responses.

\subsection{Data analysis and risk weighting process}

The weighting procedure requires that eligible indicators must reach a minimum data threshold by having at least two of the following supporting sources: government data, field research data (surveys and in-depth interviews) or a minimum of three independent expert surveys. The quantity and quality of supporting data sources and the number of expert surveys determine robust data. The more robust data the indicators contain, the more heavily they are weighted. Indicators with inadequate supporting data are still noted in the risk profile to highlight where data gaps are found for future data collection.

Empirical and expert data were combined using a few weighting steps. First of all, findings and figures from document analysis and household survey data were verified, coded and classified into risk indicators corresponding to the categories in the WCV index. Three groups of researchers (each group responsible for one of the three risk pillars physical risk, economic risk and security and political risk) interpreted and analysed the documentation and interview transcripts related to their topic. To ensure the quantification of qualitative and quantitative data is consistent, one scale for assessing the likelihood of individual risk indicator (Frequent: 0.76-1; Probable: 0.51-0.75; Occasional: 0.26-0.5; Remote: $0-0.25$ ) and one for the impact (Catastrophic: 0.76-1; Significant: 0.51-0.75; Moderate: $0.26-0.5$; Low: $0-0.25$ ) were used when converting the data into numbers and plugged into equations for measuring risk scores. The baseline data were used to allow experts to measure the relatively concrete levels of likelihood and impact of individual indicators. This step required a lot of time for fact-checking and triangulation, but this method helps eliminate as much subjectivity from the process as possible and create a quantifiable metric needed for the risk scoring system.

In the next step, the scores of likelihood and impact of risk indicators were imported into Excel in which a risk assessment equation was applied to measure risk scores. We developed a 10-point scale, 1 representing a risk that is less likely or undetectable and $10 \mathrm{a}$ risk that is very likely to occur in the near future. Scores are interpreted in Table 4. In the data visualisation step, colours were used to present the data and communicate how much a risk indicator scores. To make the WCV risk profile more communicative, we used a traffic light system in this research where red symbolises a very high-level of risk, red orange presents a high-level, yellow a medium and green a low or undetectable risk. By doing so, the relative risk indicators that are in highest need of action stand out naturally.

To ensure objective evaluation, our researchers developed an agreed-upon comprehensive coding system that allows for enhancing as much transparency of the evaluation as possible. We also have assigned equal weights to the risk indicators when measuring data. However, in a risk category in a specific local context, some risk indicators may have higher likelihood and deeper impact than the others. This means that justifying the contextual varieties is an important step to determine which risk indicators are weighed 


\begin{tabular}{|c|c|c|c|}
\hline Level of risk & Scores & Level descriptors & Measuring \\
\hline Very high & $7.51-10$ & $\begin{array}{l}\text { The issue area represents a key threat to undermine the security and } \\
\text { adaptive capacity of women } \\
\text { Well-being of women and their families are at stake and action needs to } \\
\text { be taken by the government and development partners as soon as } \\
\text { possible to protect them }\end{array}$ & vulnerabili \\
\hline \multirow[t]{2}{*}{ High } & \multirow[t]{2}{*}{$5.01-7.5$} & \multirow{2}{*}{$\begin{array}{l}\text { The issue area represents a potential threat that can cause severe and } \\
\text { widespread impacts if it intersects with other existing threats } \\
\text { More attention and investment is required for risk reduction, disaster } \\
\text { preparedness and to build women-driven resilience }\end{array}$} & 113 \\
\hline & & & \\
\hline Medium & $2.51-5.0$ & $\begin{array}{l}\text { Medium risk scores indicate that while the specific risk has been } \\
\text { mitigated, future changes or impacts from other risk dynamics that are } \\
\text { detectable could destabilise current risk management gains }\end{array}$ & \\
\hline Low & $0-2.5$ & $\begin{array}{l}\text { Low-risk scores mean that either the issue area has been addressed or no } \\
\text { possible impacts on women are detectable }\end{array}$ & $\begin{array}{r}\text { Table } 4 . \\
\text { k scoring system }\end{array}$ \\
\hline \multicolumn{3}{|c|}{ Source: Adapted from IPCC (2014), Stuart et al. (2020); Asian Development Bank (2017) } & \\
\hline
\end{tabular}

more heavily. Not only does this undermine the equal weight in the WCV index but it also allows for comparing how the risk scores improve or change over time.

\section{Results and discussion}

Because Ben Tre Province is so susceptible to climate extremes and sea level rise, it is in danger of a "double crisis" should the negative effects of climate change intersect with human stressors such as economic shocks, poverty, pollution and ecological conflicts. While the province has been implementing a growing number of state policies to mitigate the humanitarian and economic impacts, the unprecedented droughts and other environmental crises over the past five years that have caused unbearable damage to local people to demonstrate that there are gaps in building responsive capacity and resilience in this rural province. A lack of response policies specifically designed for women is another problem we found in this research. Ben Tre Government recognises the pressing need for the local women to be empowered with adaptive capacity, but risk dynamics and areas in urgent need of action remain under-researched and are not fully recognised in the province's disaster risk reduction and climate change action plans.

The WCV profile reveals a relatively high-level of risk facing women in Ben Tre. Of the 12 risk categories shown in the WCV index dashboard (Figure 2), seven categories have high-risk scores, five of which are found in physical and economic risk sectors. In the security and political risk, categories of stability, human security and governance have lowest scores, demonstrating a fairly politically favourable condition in the province. The medium risk scores captured in land and infrastructure categories (4.46 and 4.55, respectively) reveal promising determinants of the adaptation of women in this rural province. The WCV profile shows that the Ben Tre Government is already working to improve rural infrastructure assets and political environment to address the local basic needs of women, but more needs to be done to reduce the high-risk scores in terms of ecology, water, demographics and rural livelihoods. 


\section{IJCCSM \\ 14,2}

\section{4}

Figure 2.

Women climate risk profile

\section{Overview of Rural Women Climate Risk Profile in Ben Tre Province \\ Very high risk: $7.51-10 \quad$ High risk: $5.01-7.50$ Medium risk: $2.51-5.0$ Low risk: 0 - 2.50}

Physical Risk Economic Risk Security and Political Risk

\begin{tabular}{l|c|c|c|c|c|}
\hline & & & & & \\
\hline Water & 6.34 & Economy & 6.31 & Demographics & \\
\hline Land & 4.46 & Livelihoods & 6.08 & Governance & 4.82 \\
\hline Climate & 6.25 & Infrastructure & 4.50 & Stability & 4.79 \\
\hline Ecology & 6.78 & & Cyber security & 5.76 \\
& & & Human security & 4.48 \\
\hline
\end{tabular}

\subsection{Physical risk}

Ben Tre is noticed for its abundant freshwater, diverse ecosystems from river to near-shore to marine and fertile land. However, ecology and water are the two risk categories that have highest risk scores, 6.78 and 6.34, respectively, followed by climate risk category, suggesting the growing physical risks in the province (Figure 3).

The water category has the second highest mean score in physical risk, meaning that the water security is highly at risk. As prolonged droughts continue and less water from the upstream Mekong River comes downstream during the dry season, many rivers, lakes and

\section{Ben Tre WVC Index: Physical Risk}

\begin{tabular}{|l|l|l|l|}
\hline Very high risk: $7.51-10$ & High risk: $5.01-7.50$ & Medium risk: $2.51-5.0$ & Low risk: 0 - 2.50 \\
\hline
\end{tabular}

\begin{tabular}{|c|c|c|c|}
\hline Category & Risk score & Indicator & Risk score \\
\hline
\end{tabular}

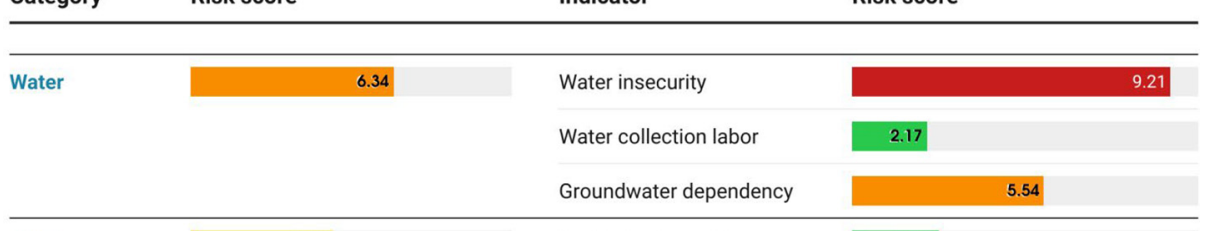

\begin{tabular}{|c|c|c|c|c|}
\hline \multirow[t]{3}{*}{ Land } & 4.46 & Arable land scarcity & 2.49 & \\
\hline & & Disaster-prone land area & & 7.45 \\
\hline & & Geophysical disasters & 2.40 & \\
\hline \multirow[t]{3}{*}{ Climate } & 6.25 & Climate extremes & & 7.83 \\
\hline & & Climate-related illness & 2.64 & \\
\hline & & Climate-sensitive diseases & & 6.72 \\
\hline \multirow[t]{3}{*}{ Ecology } & 6.78 & Biodiversity loss & & 7.74 \\
\hline & & $\begin{array}{l}\text { Degraded ecosystem } \\
\text { services }\end{array}$ & & 8.17 \\
\hline & & Eco gender gap & 2.08 & \\
\hline
\end{tabular}


canals are contaminated due to saline intrusion and wastewater discharges. These have led to frequent dire water scarcity and women appear to suffer most given their specific hygiene needs. These problems are reflected in the extremely high score in water insecurity (9.21). In coastal communes, water scarcity also leads rural women to intensively extract more groundwater for domestic use and personal hygiene. This presents a high-risk of arsenic poisoning and other water-related diseases (Groundwater dependency, 5.54).

Although rural women in Ben Tre suffer from water insecurity, their responsibility for household water supply is equally shared by their husbands or male members in the family. Men are often responsible for transporting fresh water from public water supply stations in the drought season, given the local traditional notion that men shoulder heavy and arduous tasks. This is reflected in the low-risk score in the division of water collection labour in families (2.17).

The land category reveals a medium level of risk (4.46) thanks to the very low-risk scores from arable land scarcity (2.49) and geophysical disasters (2.40). But the arable land area that is prone to climate hazards is scored as high-risk (7.45), given that increased losses of arable land have been reported in recent years. This risk category finds that arable land is not scarce, but crops are projected to be more susceptible to droughts, pests, unpredictable downpours and tidal flooding.

In the climate category, extreme weather conditions pose unfavourable impacts on women's health and livelihoods. As most of rural women engage in outdoor agricultural activities, such as coconut farming and floral crops, their jobs face very high-risk from the changing climate (7.83). About two-thirds of women respondents $(64.9 \%)$ said that they have experienced problems as a result of the uncharacteristically hot days, such as poor work performance, sunstroke and unfavourable moisture level and other mental health problems due to displacement or crop losses. Changes in climate have also led to an increase in infectious diseases, such as malaria, cholera, yellow fever and dengue, over the past 10 years. However, as the number of rural women who are supported by National Women and Children Health-care Programs has remarkably increased, the climate change impacts on women's health are expected to be mitigated in the near future.

The ecology category scored the highest risk (6.78) due to dire ecosystem services degradation (8.17), followed by severe biodiversity loss resulting in poor health of local forests (7.74). These very high-risk scores reveal the likelihood of ecological crisis in the province, indicating an urgent need for action to be made. New forest protection law and regulations have reduced the deforestation and biodiversity depletion albeit at a very slow pace. Some restored mangrove and near-shore ecosystems in the province have opened new income sources for local women who work in fishery, eco-tourism and forestry-related jobs, as reflected in the fairly low-risk score in gender-equal access to ecosystem services benefits (Eco gender gap, 2.08).

\subsection{Economic risk}

The WCV risk profile shows that climate and human-induced stressors are spread across the economic risk categories (Figure 4). Despite the positive economic growth in recent years, women in Ben Tre enjoy an average gross national income (GNI) per capita of less than US\$2,200 (Ben Tre People's Committee, 2021). Low household income results in poor housing quality and little available funds for better preparedness to bear the costs of climate change adaptation (Smit and Pilifosova, 2001). The growth of GNI per capita of women population in Ben Tre is projected to be stagnant, if not reduced, in the coming years due to the post-COVID economic downturn. Crop losses reported in recent years add a significant threat to the women's GNI per capita growth. This reflects a high-risk score in GNI per 
IJCCSM

14,2

116

\section{Ben Tre WCV Index: Economic Risk}

\section{Very high risk: $7.51-10$ High risk: 5.01 - 7.50}

Medium risk: $2.51-5.0$ Low risk: $0-2.50$

\begin{tabular}{|c|c|c|c|}
\hline Categories & Risk score & Indicators & Risk score \\
\hline \multirow[t]{8}{*}{ Economy } & 6.31 & GNI per capita decline & 5.28 \\
\hline & & Unequal property rights & 7.04 \\
\hline & & Income diversification & 7.28 \\
\hline & & Rural unemployment & 6.79 \\
\hline & & Economic dependency & 7.12 \\
\hline & & Financial illiteracy & 7.21 \\
\hline & & Informal economy & 5.32 \\
\hline & & Tax burdens & 1.54 \\
\hline \multirow[t]{6}{*}{ Livelihoods } & 6.08 & Cultivation recession & 8.09 \\
\hline & & Husbandry recession & 6.08 \\
\hline & & Aquaculture recession & 6.57 \\
\hline & & Wild-capture fishery recession & 7.57 \\
\hline & & $\begin{array}{l}\text { Labor-intensive industry } \\
\text { recession }\end{array}$ & 4.27 \\
\hline & & Economic stagnancy & 3.90 \\
\hline \multirow[t]{5}{*}{ Infrastructure } & 4.50 & Poor public infrastructure & 3.57 \\
\hline & & Poor digital infrastructure & 5.60 \\
\hline & & Inadequate housing & 3.20 \\
\hline & & Lack of emergency shelters & 7.20 \\
\hline & & Engery insecurity & 2.46 \\
\hline
\end{tabular}

Figure 4.

Economic risk scores

capita indicator (5.28), calling for action to improve women's income - an important determinant of adaptive capacity.

The income sources of rural women are not diverse, as the majority of survey respondents (83\%) informed that they rely on one main income source (e.g. coconut crop) and an additional daily income from seasonal, unstable and low-cost jobs. In total, $78 \%$ of respondents also said that they are unable to find better-paid, long-term jobs, especially in the low water season when all crops are harvested or unable to grow. Low, unstable personal income and high unemployment rate (4.41\% among women aged 18 and above, 
Ben Tre People's Committee, 2021) in rural populations lead women to persistent economic dependency on their husbands. Although the law on gender equality has been reinforced since 2006, for many rural women in Ben Tre that law means little in practice since the women's property rights remain unequal, given the well-established patriarchal culture that empowers men to lead the family and own all important assets, from house, to land, to financial means. This situation prevents the local women from rights to inherit and control land and other productive resources. In drought seasons, their family's financial security becomes fragile due to crop losses and increasing expenses in relation to fresh water, energy and food. Some women and their daughters $(31.3 \%)$ have no choice but to work as informal workers in grey economic sectors, such as coconut processing and labour-intensive seafood factories, with some human security risks, including lack of protection of labour laws, health insurance and women's rights violations (see the security and political risk). The climateinduced economic crisis is remarkably exacerbated during a pandemic, such as COVID-19, threatening to undermine the resilience of rural women. A few women $(5.9 \%)$ have resorted to risky "black credit," among other informal financial activities, to address their urgent needs.

These findings are reflected in the high-risk scores in income diversification (7.28), financial illiteracy (7.21), economic dependency (7.12), unequal property rights (7.04), rural unemployment (6.79) and informal economy (5.32). Addressing these areas of high-risk needs to focus on the first two risk indicators (income diversification and financial illiteracy) in advance of the others. Timely funding and policies are needed to aid women in diversifying their incomes and increasing their knowledge of personal financial management, budgeting and investing to avoid or cope with financial and economic shocks. By doing so, solutions to these two risk indicators will naturally contribute to reducing the risk scores in other risk indicators.

In the livelihoods risk category, a very high-risk score is recorded in cultivation recession (8.21), followed by wild-capture fishery recession (7.57). Given that the majority of rural women are highly dependent on aqua- and agriculture-based occupations for subsistence, their livelihoods are expected to be in danger of the intensity of climate change. Reduced Mekong fish migration flowing downstream - the primary protein source on which $37 \%$ of local women rely - is another threat that hampers the adaptation of women. Lower risk scores are found in husbandry recession (6.08) and aquaculture recession (6.57). Women's heavy dependency on climate-vulnerable livelihoods, such as cultivation, husbandry, freshwater and brackish water aquaculture, poses significant risk to their own economic security and increases the likelihood of a "double crisis" should economic shocks intersect with climate hazards.

Infrastructure category presents the lowest risk score in the economic risk (4.50). In the past decade, increased investments in infrastructure development through socialisation (build-operate-transfer projects) have provided intricate networks of roads, bridges, schools, health centres and markets in Ben Tre Province. Those infrastructure assets help local women fulfil their basic needs. Standardised $3.5 \mathrm{~m}$ wide roads pervade across the rural communes, resulting in a significant improvement in local housing conditions, among other benefits. These are reflected in very low-risk scores in indicators of poor public infrastructure (3.57) and inadequate housing (3.20).

The highest risk score is found in indicator of lack of emergency shelters (7.20), which demonstrates serious risk to human security during conflicts, natural disasters and other emergencies. While Ben Tre has not frequently experienced deadly flooding and typhoons in recent decades, lack of gendered emergency shelters and temporary housing may increase the vulnerability of women when they face family violence or disasters. This risk score calls
Measuring women climate vulnerability 
IJCCSM 14,2 for the government to reconsider its disaster risk reduction and management plans to reallocate appropriate resources for gendered emergency shelters.

\subsection{Security and political risk}

High-risk scores are recorded across risk categories of demographics (6.34) and cyber security (5.76) (see Figure 5). The demographics category reveals a very likely risk from negative demographics shifts in population (7.64). Gender imbalance and ageing population are the most urgent issues in need of action found in Ben Tre. Number of women of workingage in the province's rural population is relatively high (approximately 61.4\% of the total population) as more men have migrated out of the villages in recent years. Yet labour force participation among adult women is low due to a high unemployment rate, as described in the economic risk. Low-educated and unskilled women make up a majority of the female population in rural areas, preventing them from better-paid jobs in the labour market and diversification of incomes. This explains the high score in labour market disadvantage (5.67). Further, dependency ratio in women-headed families is high (5.36) and continues to increase thanks to the aging population trend. Our household survey results found increases in the elderly and youth dependency ratios, putting additional pressure on women to cover schooling, health care and other expenses for the elderly and children in their families. As a result, pressure to increase household incomes to sustain basic family needs is an immediate burden that rural women are forced to shoulder.

The governance category highlights a need for greater women empowerment and participation in local decision-making processes. Underrepresentation of women in local politics and policy arenas has led to a lack of gendered adaptation policies that are designed in favour of women. These challenges are identified as a high score in political underrepresentation (5.77). The province's limited progress in adaptation and mitigation, in conjunction with limited participation of women in local climate change governance and action, are factors that increase the likelihood of climate action failure (6.00). Cultural norms, prejudices and discrimination against women pose a high-risk of insulating and impeding women from policy preferences or opportunities necessary for them to sustain their livelihoods. Document analysis found that about 100 projects from non-state actors have been introduced to the province over the past decade. Nonetheless, many of them have primarily focussed on construction, emergency disaster relief and training areas with less emphasis on adaptive capacity and resilience building of rural women. This is reflected in the high-risk score in gender-sensitive governance failure (6.50), which means that women need to be much more empowered and recognised as change agents in multi-actor governance of climate change.

Another challenge comes from social fragmentation (6.38). Ecological conflicts are prominent problems as a result of decades-long unsustainable development in Ben Tre, placing women even more at risk. Deadly environmental pollution caused by exportprocessing factories and craft villages has been the driver of social tensions in recent years (Vietnam News Agency, 2020). Land disputes in development projects are another unsettled political challenge fuelling social disorder in some communes (Ministry of Natural Resources and Environment, 2018). Together with the above-analysed risks of livelihood crises, rural unemployment, economic disparities and political marginalisation, ecological conflicts and disputes over resources are among the high-likelihood and high-impact risks that affect women, especially poor, women-headed families and thus further fray social cohesion.

Ben Tre has witnessed an increasing prevalence of internet and smartphone usage in recent years. In rural communes, $92.6 \%$ of survey respondents use smartphones and $60.9 \%$ 
Ben Tre WCV Index: Security and Political Risk

\begin{tabular}{|c|c|c|c|}
\hline Very high risk: & 10 High risk: $5.01-7.50$ & Medium risk: $2.51-5.0$ Low & -2.50 \\
\hline Categories & Risk score & Indicators & Risk score \\
\hline \multirow[t]{3}{*}{ Demographics } & 6.34 & Negative demographics shifts & 7.64 \\
\hline & & Dependency ratio & 5.36 \\
\hline & & Labor market disadvantage & 5.67 \\
\hline \multirow[t]{4}{*}{ Governance } & 4.82 & Political underrepresentation & 5.77 \\
\hline & & Climate action failure & 6.00 \\
\hline & & $\begin{array}{l}\text { Gender-sensitive governance } \\
\text { failure }\end{array}$ & 4.55 \\
\hline & & Informality & 1.10 \\
\hline \multirow[t]{4}{*}{ Stability } & 4.79 & Social fragmentation & 6.38 \\
\hline & & Social security collapse & 0.81 \\
\hline & & Women's marginalization & 6.48 \\
\hline & & Women's disillusionment & 3.50 \\
\hline \multirow[t]{4}{*}{ Cyber security } & 5.76 & Digital inequality & 2.31 \\
\hline & & Digital illiteracy & 7.57 \\
\hline & & Social media dependency & 5.18 \\
\hline & & Cypersecurity failure & 6.24 \\
\hline \multirow[t]{5}{*}{ Human security } & 4.48 & Environmental misconception & 6.80 \\
\hline & & Gender-based violence & 2.17 \\
\hline & & Women's rights misperception & 5.82 \\
\hline & & Health crisis & 5.10 \\
\hline & & NTS threats & 3.48 \\
\hline
\end{tabular}

Table: Quang NM · Source: Mekong Environment Forum · Created with Datawrapper

\section{Measuring women climate vulnerability}

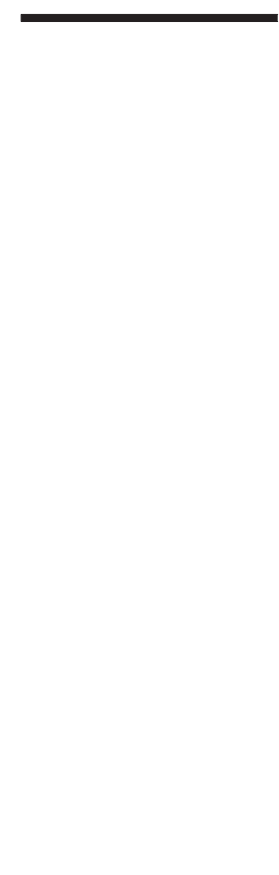

Figure 5. Security and political risk scores

browse the internet daily. Rural women prefer using internet-connected smartphones mainly for communication, information and entertainment. Decreasing prices of smartphones and internet services are facilitating the growth of rural internet development in Vietnam and Ben Tre in particular (Digital inequality risk score, 2.31). However, low digital literacy and awareness of cyber security law poses very high-risk to their safety, as reflected in digital illiteracy (7.57).

In total, $57.9 \%$ of respondents browsing the internet reported that social media are their important and preferable sources of information. This shows a soaring risk of misinformation and exposure of women to crimes and gender-based violence in the online world (Social media dependency, 5.18). Our policy analysis shows that there is a lack of cyber security measures in the province to protect women in the online world. The law of cyber security has been adopted by the National Assembly and took effect in January 2019, 
IJCCSM 14,2 but $88.1 \%$ of survey respondents are not fully aware of the law, illegal acts and contents in the cyberspace, as well as potential threats women must take into account while staying connected (Cyber security failure, 6.24). As non-traditional crimes are mushrooming in mostused digital platforms in Vietnam, such as Facebook and Youtube, rural women are in need of protection to insulate them from cybercrimes, including phishing scams, human trafficking, sexual abuse and violence. Fake news and misinformation are among other threats challenging women's safety and decision-making during crisis, especially in the times of pandemic or climate hazards.

The medium risk score in human security (4.48) suggests a relatively bright picture of the safety of rural women thanks to a low-risk score of gender-based violence (2.17) and medium risk of non-traditional security threats (3.48). However, a large portion of women respondents $(94.1 \%)$ is unaware of environmental literacy or has misunderstandings about climate change (Environmental misconception, 6.80). Without proper understanding of the environmental challenges, women are unable to make informed decisions relating to disaster preparedness and to come up with practical solutions (IUCN, 2015).

Misperception or misinterpretation about women's rights can lead to unrelenting rights violations, domestic violence and abuse at home or at work, which are eventually stressors eliminating their ability to respond to physical-, economic- and climate-related shocks. Furthermore, the low awareness of women's rights, rule of law and justice has contributed to the continuity of well-established gender inequality and discrimination in rural Ben Tre, especially in terms of property rights as analysed above. Failure to protect women's rights places rural women in the context in which their rights are least protected, and their ability to control land and other productive resources for development is constrained. A high-risk score in women's rights misperception (5.82) shows that these vulnerabilities are likely to be exacerbated in the event of climate hazards.

\section{Conclusion}

This research has identified 12 risk categories with 51 indicators that cover the primary issue areas in the rural contexts and are represented in a wheel-shaped WCV index. Risk indicators are climate-induced and human-caused. They shape the vulnerabilities and constrain the adaptive capacity of rural women.

As the WCV profile of Ben Tre points out, risks that are very likely to occur or be exacerbated in the near future are found across multiple high-risk category scores. This provides a reasonably worrisome picture of women's vulnerability in Ben Tre. While the risks found in the WCV assessment are dire, the WCV profile, on the other hand, offers an opportunity to identify priority areas that need to be addressed.

The results of the case study in Ben Tre Province demonstrate the importance of using the WCV index and how this methodology can be of use to other local contexts in developing countries that share many of the same issues. The WCV index provides a holistic assessment of the risk indicators relevant for assessing the adaptive capacity of women across climate-sensitive sectors. In our field study, we have double-checked if the WCV index overlooks any risk indicators that are present in the local context through in-depth interviews with experts and group discussion with local women, which is also perhaps underrepresented in literature. However, as the WCV index is designed for localised climate vulnerability assessment, it allows users to expand and include new risk indicators, if needed, to ensure that the WCV index fit into their distinct physical, economic and political contexts.

By providing evidence-based information and quantifiable metrics about the cascading risks that women face, the WCV index enables local governments to improve gender- 
sensitive climate policy reforms, prioritise actions and drive climate funds to assist local women where they need most. In addition, given the dire and deep-rooted patriarchal culture in many societies, the publication of WCV index will be part of the endeavours to make tangible progress towards gender equality in climate adaptation.

The WCV assessment results shed new light on to which degree and in which environmental issues the state policy responses have not successfully addressed at the local level. The WCV index enables decision makers to develop a cross-sectoral framework that would effectively and comprehensively capture and address both the climatic and nonclimatic stressors. The WCV index allows for better understanding of the linkages of risk areas and calls for expert judgment in regard to dealing with overlaps and ensuring that solution to address one issue area does not pose adverse impacts on or undermine another. Accordingly, the WCV methodology could be adjusted to assess the climate risk vulnerability in other sectors.

\section{References}

Andrijevic, M., Cuaresma, J.C., Lissner, T., Thomas, A. and Carl-Friedrich, S. (2020), "Overcoming gender inequality for climate resilient development”, Nature Communications, Vol. 11 No. 1 , p. 6261.

Arekapudi, N. and Almodóvar-Reteguis, N. (2020), "Women's property rights are the key to economic development”, World Bank Blogs, available at: https://blogs.worldbank.org/developmenttalk/ womens-property-rights-are-key-economic-development (accessed 11 February 2021).

Asian Development Bank (2017), "Climate change assessment: climate risk and vulnerability assessment”, available at: www.adb.org/sites/default/files/linked-documents/48480-003-cca.pdf (accessed 8 February 2021).

Balabanova, E.S. (2007), “Women's economic dependency: nature, causes and consequences", Sociological Research, Vol. 46 No. 2, pp. 5-21.

Banerjee, S., Hussain, A., Tuladhar, S. and Mishra, A. (2019), "Building capacities of women for climate change adaptation: insights from migrant-sending households in Nepal", Climatic Change, Vol. 157 Nos 3/4, pp. 587-609.

Ben Tre People's Committee (2021), "Report on environment in Ben Tre province, 2016-2020", Decision No.301/QD-UBND dated 8 February 2021.

Binh, T.T. (2018), “Climate change and marriage migration out of the Mekong Delta”, Mekong Eye, available at: www.mekongeye.com/2018/11/29/climate-change-and-marriage-migration-out-ofthe-mekong-delta/ (accessed 18 February 2021).

Boetto, H. and McKinnon, J. (2013), "Rural women and climate change: a gender-inclusive perspective", Australian Social Work, Vol. 66 No. 2, pp. 234-247.

Carew-Reid, J. (2008), "Rapid assessment of the extent and impact of sea level rise in Vietnam", climate change discussion paper 1, International Centre for Environmental Management, Brisbane, Australia.

Chanana-Nag, N. and Aggarwal, P.K. (2020), "Woman in agriculture and climate risks: hotspots for development”, Climatic Change, Vol. 158 No. 1, pp. 13-27.

Chant, S. (1997), "Women-headed households: poorest of the poor? Perspectives from Mexico, Costa Rica and the Philippines", IDS Bulletin, Vol. 28 No. 3, pp. 26-48.

Connor, J., Madhavan, S., Mokashi, M., Amanuel, H. and Bartz, D. (2020), "Health risks and outcomes that disproportionately affect women during the Covid-19 pandemic: a review", Social Science and Medicine, Vol. 266, p. 113364, doi: 10.1016/j.socscimed.2020.113364.

de Wit, J. (2019), Urban Poverty, Local Governance and Everyday Politics in Mumbai, Routledge India, New Delhi. 
IJCCSM 14,2

Denton, T. (2010), "Climate change vulnerability, impacts and adaptation: why does gender matter?", Gender and Development, Vol. 10 No. 2, pp. 10-20.

Di Cesare, M. (2014), “Women, marginalization and vulnerability: introduction”, Genus, Vol. 70 Nos 2/3, pp. 1-6.

Djoudi, H., Locatelli, B., Vaast, C., Brockhaus, M. and Sijapati, B. (2016), "Beyond dichotomies: Gender and intersecting inequalities in climate change studies", Ambio, Vol. 45, pp. 248-262.

Dube, S. (2014), "Support women to build their adaptive capacity and resilience. Conflict-sensitive Adaptation: use human rights to build social and environmental resilience", Brief 9. Indigenous Peoples of Africa Co-ordinating Committee and IUCN Commission on Environmental, Economic and Social Policy.

Fairbairn, J. (2020), "Before \#MeToo: violence against women social media work, bystander intervention and social change", Societies, Vol. 10 No. 3, p. 51, doi: 10.3390/soc10030051.

FAO (2017), "The role of gender in climate-smart agriculture", available at: www.fao.org/climate-smartagriculture-sourcebook/enabling-frameworks/module-c6-gender/c6-overview/en/ (accessed 18 March 2021).

Figueiredo, P. and Perkins, P.E. (2013), "Women and water management in times of climate change: participatory and inclusive processes", Journal of Cleaner Production, Vol. 60, pp. 188-194.

Fortnam, M., Brown, K., Chaigneau, T., Crona, B., Daw, T.M., Gonçalves, D., Revmatas, M. and SchulteHerbruggen, B. (2019), "The gendered nature of ecosystem services", Ecological Economics, Vol. 159, pp. 312-325.

Fritsche, I., Cohrs, J.C., Kessler, T. and Bauer, J. (2012), "Global warming is breeding social conflict: the subtle impact of climate change threat on authoritarian tendencies", Journal of Environmental Psychology, Vol. 32 No. 1, pp. 1-10.

Gerrard, M. (2016), Climate Change and Human Trafficking after the Paris Climate Agreement, Sabin Center for Climate Change Law, Columbia Law School, New York, NY.

Gevers, A., Musuya, T. and Bukuluki, P. (2020), "Why climate change fuels violence against women", UNDP Blog, available at: www.undp.org/content/undp/en/home/blog/2020/why-climate-changefuels-violence-against-women.html (accessed 22 February 2021).

Glazebrook, T. (2011), "Women and climate change: a case-study from northeast Ghana”, Hypatia, Vol. 26 No. 4, pp. $762-782$.

Grabe, S., Grose, R.G. and Dutt, A. (2014), “Women's land ownership and relationship power: a mixed methods approach to understanding structural inequities and violence against women", Psychology of Women Quarterly, Vol. 39 No. 1, pp. 7-19.

Gupta, J., van der Leeuw, K. and de Moel, H. (2007), “Climate change: a 'glocal' problem requiring 'glocal' action”, Environmental Sciences, Vol. 4 No. 3, pp. 139-148.

Howard, G., Calow, R., Macdonald, A. and Bartram, J. (2016), "Climate change and water and sanitation: likely impacts and emerging trends for action", Annual Review of Environment and Resources, Vol. 41 No. 1, pp. 253-276.

Indrawati, S.M. (2015), "What you need to know about energy and poverty", World Bank Blogs, available at: https://blogs.worldbank.org/voices/what-you-need-know-about-energy-and-poverty (accessed 28 November 2020).

International Organisation for Migration (2017), "The climate change-human trafficking nexus", available at: $\mathrm{https} / /$ publications.iom.int/system/files/pdf/mecc_infosheet_climate_change_nexus. pdf (accessed 21 November 2020).

IPCC (2014), “Assessing and managing the risks of climate change”, available at: www.ipcc.ch/site/assets/ uploads/2018/03/WGIIAR5_SPM_Top_Level_Findings-1.pdf (accessed 20 November 2020).

IUCN (2015), "Gender and climate change: strengthening climate action by promoting gender equality", available at: www.iucn.org/sites/dev/files/import/downloads/gender_and_climate_change_issues_ brief_cop21_04122015.pdf (accessed 4 February 2021). 
Kristjanson, P. (2019), "Trees and forests are Key to fighting climate change and poverty. So are women”, World Bank Blogs, available at: https://blogs.worldbank.org/voices/trees-forests-keyfighting-climate-change-poverty-women (accessed 11 February 2021).

Lama, P., Hamza, M. and Wester, M. (2020), "Gendered dimensions of migration in relation to climate change", Climate and Development, Vol. 13 No. 4, pp. 326-336.

Landis, W.G., Durda, J.L., Brooks, M.L., Chapman, P.M., Menzie, C.A., Stahl, R.G., Jr and Stauber, J.L. (2013), "Ecological risk assessment in the context of global climate change", Environmental Toxicology and Chemistry, Vol. 32 No. 1, pp. 79-92.

Leonard, M., (1998), "Women and the informal economy", in Leonard, M. (Ed.), Invisible Work, Invisible Workers, Palgrave Macmillan, London, pp. 113-134.

Maôdra-Sawicka, M., Nord, J., Paliszkiewicz, J. and Lee, T. (2020), “Digital media: empowerment and equality", Information, Vol. 11 No. 4, p. 225, doi: 10.3390/info11040225.

Ministry of Natural Resources and Environment (2016), Climate Change and Sea Level Rise Scenarios in Vietnam, Ministry of Natural Resources and Environment Press, Hanoi.

Ministry of Natural Resources and Environment (2018), "Ben Tre: land disputes still remain complicated", available at: https://baotainguyenmoitruong.vn/ben-tre-tinh-trang-khieu-nai-vedat-dai-con-dien-bien-phuc-tap-230641.html (accessed 11 February 2021).

Mlambo, C. and Kapingura, F. (2019), "Factors influencing women political participation: the case of the SADC region”, Cogent Social Sciences, Vol. 5 No. 1, doi: 10.1080/23311886.2019.1681048.

Momtaz, S. and Asaduzzaman, M. (2020), Climate Change Impacts and Women's Livelihood Vulnerability in Developing Countries, Routledge, Milton Taylor \& Francis Group, Oxford.

Muthien, B. (2000), "Human security paradigms through a gendered lens", Agenda, Vol. 43 No. 43, pp. 46-56.

Nasiritousi, N., Hjerpe, M. and Linnér, B.O. (2016), "The roles of non-state actors in climate change governance: understanding agency through governance profiles", International Environmental Agreements: Politics, Law and Economics, Vol. 16 No. 1, pp. 109-126.

Nature Climate Change (2019), "Gender in conservation and climate policy”, Vol. 9 No. 255, doi: 10.1038/ s41558-019-0448-2.

Nyirongo, V. (2019), "Rural women's economic empowerment and the road to 2030: agency for climate action", UN Chronicle, available at: www.un.org/en/un-chronicle/rural-women\%E2\%80\%99seconomic-empowerment-and-road-2030-agency-climate-action (accessed 4 March 2021).

OECD (2013), "Women and financial literacy", available at: www.oecd.org/daf/fin/financial-education/ TrustFund2013_OECD_INFE_Women_and_Fin_Lit.pdf (accessed 4 March 2021).

OECD (2018), "Bridging the digital gender divide: include, up skill, innovate", available at: www.oecd. org/digital/bridging-the-digital-gender-divide.pdf (accessed 11 March 2021).

Quang, N.M. (2020), "Climate governance in Vietnam: issues need to be addressed”, Vietnam Journal of Science and Technology, Vol. 744 No. 5, pp. 48-51.

Quang, N.M. (2021), "Climate change and pandemic: linkages, impacts and collective solutions", Vietnam Journal of Science and Technology, Vol. 745 No. 4, pp. 11-13.

Resurrección, B.P. (2013), "Persistent women and environment linkages in climate change and sustainable development agendas", Women's Studies International Forum, Vol. 40, pp. 33-43.

Smit, B. and Pilifosova, O. (2001), "Adaptation to climate change in the context of sustainable development and equity”, in McCarthy, J., Canziani, O., Leary, N. and White, K., (Eds), Climate Change 2001: Impacts, Adaptation and Vulnerability, Cambridge University Press, Cambridge, United Kingdom, pp. 877-912.

Sofuoğlu, E. and Ay, A. (2020), "The relationship between climate change and political instability: the case of MENA countries (1985:01-2016:12)", Environmental Science and Pollution Research, Vol. 27 No. 12, pp. 14033-14043.

Stuart, J., Yozell, S. and Rouleau, T. (2020), The Climate and Ocean Risk Vulnerability Index, Stimson Center, Washington, DC. 
IJCCSM 14,2

Tschakert, P. (2012), "From impacts to embodied experiences: tracing political ecology in climate change research", Geografisk Tidsskrift-Danish Journal of Geography, Vol. 112 No. 2, pp. 144-158.

UN (2018), "Gender equality in land rights, ownership vital to realizing 2030 agenda, women's commission hears amid calls for data collection on tenure security", available at: www.un.org/ press/en/2018/wom2143.doc.htm (accessed 6 December 2020).

UN Human Rights (2012), Women and the Right to Adequate Housing, UN Geneva.

UN Population Fund (2009), "Overview: women at the forefront", available at: www.unfpa.org/sites/ default/files/pub-pdf/climateconnections_1_overview_1.pdf (accessed 11 March 2021).

UN Water (2010), "Climate change adaptation: the pivotal role of water", available at: www.unwater. org/publications/climate-change-adaptation-pivotal-role-water/ (accessed 6 February 2021).

UN Women (2020), “Digital technology can empower women, but. ..”, available at: https:/georgia.unwomen. org/en/news/stories/2020/05/digital-technology-can-empower-women (accessed 11 April 2021).

UN Women Watch (2022), "Women, gender equality and climate change”, available at: www.un.org/ womenwatch/feature/climate_change/factsheet.html (accessed 3 April 2021).

UNDP (2013), "Overview of linkages between gender and climate change”, available at: www.undp.org/ content/dam/undp/library/gender/Gender\%20and\%20Environment/PB1_Africa_OverviewGender-Climate-Change.pdf (accessed 14 April 2021).

UNFCCC (2015), "Strengthening gender considerations in adaptation planning and implementation in the least developed countries", available at: www4.unfccc.int/sites/NAPC/Documents\%20NAP/ UNFCCC_gender_in_NAPs.pdf (accessed 26 March 2021).

UNFCCC (2017), "Gender, climate change and water connections", available at: https://unfccc.int/files/ adaptation/knowledge_resources/databases/partners_action_pledges/application/pdf/wedo_ furtherinfo_water_190411.pdf (accessed 26 March 2021).

UNFCCC (2019a), "Gender and climate change”, available at: https://unfccc.int/sites/default/files/ resource/sbi2019_inf8.pdf (accessed 13 February 2021).

UNFCCC (2019b), "Climate change increases the risk of violence against women”, available at: https://unfccc. int/news/climate-change-increases-the-risk-of-violence-against-women (accessed 13 February 2021).

Valodia, I. (2009), "Gender, poverty and taxation: an overview of a multi-country study of gender and taxation”, Agenda: Empowering Women for Gender Equity, Vol. 81, pp. 137-147.

Van Steen, F.J. (1992), “A perspective on structured expert judgment”, Journal of Hazardous Materials, Vol. 29 No. 3, pp. 365-385.

Vietnam News Agency (2020), "People in Ben Tre are highly concerned about the polluting craft villages", available at: https://baotintuc.vn/van-de-quan-tam/nguoi-dan-ben-tre-buc-xuc-vi-caclo-than-gay-o-nhiem-20200820173714941.htm (accessed 11 February 2021).

Wan, J., Li, R., Wang, W., Liu, Z. and Chen, B. (2016), "Income diversification: a strategy for rural region risk management”, Sustainability, Vol. 8 No. 10, doi: 10.3390/su8101064.

WHO (2014), Gender, Climate Change and Health, World Health Organization, Geneva, Switzerland.

Whyte, K.P. (2014), "Indigenous women, climate change impacts and action”, Hypatia, Vol. 29 No. 3, pp. 599-616.

World Economic Forum (2021), “The global risks report 2021”, Geneva.

\section{Corresponding author}

Quang N.M. can be contacted at: nmquang@ctu.edu.vn

For instructions on how to order reprints of this article, please visit our website:

www.emeraldgrouppublishing.com/licensing/reprints.htm

Or contact us for further details: permissions@emeraldinsight.com 